\title{
Hybrid endoscopic thymectomy: combined transesophageal and transthoracic approach in a survival porcine model with cadaver assessment
}

\author{
João Moreira-Pinto • Aníbal Ferreira • \\ Alice Miranda $\cdot$ Carla Rolanda $\cdot$ Jorge Correia-Pinto
}

Received: 26 August 2013/Accepted: 22 March 2014/Published online: 25 April 2014

(C) Springer Science+Business Media New York 2014

\begin{abstract}
Background Video-assisted thoracoscopic surgery thymectomy has been used in the treatment of Myastenia Gravis and thymomas (coexisting or not). In natural orifice transluminal endoscopic surgery, new approaches to the thorax are emerging as alternatives to the classic transthoracic endoscopic surgery. The aim of this study was to assess the feasibility and reliability of hybrid endoscopic thymectomy (HET) using a combined transthoracic and transesophageal approach.

Methods Twelve consecutive in vivo experiments were undertaken in the porcine model (4 acute and 8 survival). The same procedure was assessed in a human cadaver
\end{abstract}

Electronic supplementary material The online version of this article (doi:10.1007/s00464-014-3525-7) contains supplementary material, which is available to authorized users.

J. Moreira-Pinto $(\bowtie)$ - A. Ferreira - A. Miranda - C. Rolanda . J. Correia-Pinto

Life and Health Sciences Research Institute (ICVS), School of

Health Sciences, University of Minho, Campus de Gualtar, 4709-057 Braga, Portugal

e-mail: moreirapinto@gmail.com

J. Correia-Pinto

e-mail: jcp@ecsaude.uminho.pt

J. Moreira-Pinto - A. Ferreira - A. Miranda - C. Rolanda .

J. Correia-Pinto

ICVS/3B's - PT Government Associate Laboratory,

Braga/Guimarães, Portugal

J. Moreira-Pinto $\cdot$ J. Correia-Pinto

Department of Pediatric Surgery, Hospital de Braga, Braga,

Portugal

A. Ferreira $\cdot$ C. Rolanda

Department of Gastroenterology, Hospital de Braga, Braga,

Portugal afterward. For HET, an 11-mm trocar was inserted in the 2nd intercostal space in the left anterior axillary line. A $0^{\circ}$ $10-\mathrm{mm}$ thoracoscope with a $5-\mathrm{mm}$ working channel was introduced. Transesophageal access was created through a submucosal tunnel using a flexible gastroscope with a single working channel introduced through the mouth. Using both flexible (gastroscope) and rigid (thoracoscope) instruments, the mediastinum was opened; the thymus was dissected, and the vessels were ligated using electrocautery alone.

Results Submucosal tunnel creation and esophagotomy were performed safely without incidents in all animals. Complete thymectomy was achieved in all experiments. All animals in the survival group lived for 14 days. Thoracoscopic and postmortem examination revealed pleural adhesions on site of the surgical procedure with no signs of infection. Histological analysis of the proximal third of the esophagus revealed complete cicatrization of both mucosal defect and myotomy site. In the human cadaver, we were able to replicate all the procedure even though we were not able to identify the thymus.

Conclusions Hybrid endoscopic thymectomy is feasible and reliable. HET could be regarded as a possible alternative to classic thoracoscopic approach for patients requiring thymectomy.

Keywords General - Oesophageal · Surgical · Technical . Endoscopy · Thoracoscopy

Video-assisted thoracoscopic surgery (VATS) was first described in the early 1990's. Initial applications included chest exploration, pleural effusion or pneumothorax management, and limited resection of lung nodules [1-4]. As minimally invasive techniques improved, clinical 
application of VATS became progressively widespread for more complex procedures. VATS thymectomy was first described by Landreneau et al. in 1992 [5]. VATS thymectomy offers benefits of reduced immune-mediated surgical stress response and less chest trauma, with reduced impairment of postoperative pulmonary function that translates to faster recovery and fewer complications $[6,7]$. VATS thymectomy has been used for Myasthenia Gravis and for both well-encapsulated noninvasive thymomas and selected invasive thymomas [8-10].

In natural orifice transluminal endoscopic surgery (NOTES), new approaches to the thorax are emerging as alternatives to classic transthoracic endoscopic surgery. In 2007, Sumiyama et al. proposed transesophageal access to the thoracic cavity [11]. Since then, transvesical-transdiaphragmatic [12], transgastric-transdiaphragmatic [13], and transtracheal thoracoscopy [14] have also been suggested. The transesophageal approach has been considered preferable as a direct entry to the thorax and posterior mediastinum for several simple thoracic procedures in porcine models [15]. However, the transesophageal approach is typically considered to be highly risky because of possible mechanical abrasion and trauma of surrounding structures. Moreover, an ineffective esophagotomy closure can be devastating, resulting in serious infectious complications. In fact, some of the recognized difficulties of NOTES procedures, such as safe port creation, infection prevention, tissue manipulation, suturing and anastomosis establishment, seem to be particularly relevant in the transesophageal approach. In view of this, Rolanda et al. proposed the combination of single transthoracic trocar assistance with transesophageal NOTES in order to increase the safety and feasibility of more complex procedures [16]. Since then, our group has proven the safety and feasibility of hybrid transesophageal pulmonary lobectomy [17] and hybrid transesophageal left atrial appendage ligation [18] in the survival porcine model.

We hypothesized that thoracic NOTES might be appropriate for thymectomy. Thus, we designed this research protocol to assess the feasibility and reliability of hybrid endoscopic thymectomy (HET) using combined transthoracic and transesophageal approach.

\section{Methods}

Study design

Twelve female pigs (Sus scrofus domesticus) weighting $25-35 \mathrm{~kg}$ were used to perform HET. Consecutive in vivo experiments were undertaken ( 4 acute and 8 survival assessments). All surgical gastroscopic and thoracoscopic procedures were recorded. Vital signs and physiological

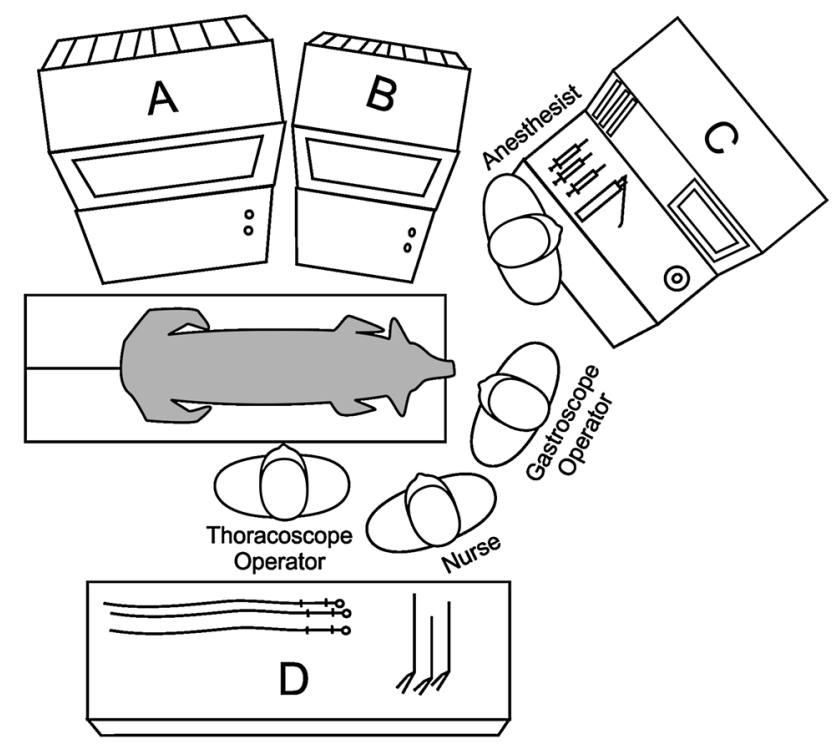

Fig. 1 Room ergonomics: $A$ thoracoscope monitor; $B$ gastroscope monitor; $C$ ventilator; $D$ back table for equipment

parameters were monitored during the experiment. The procedure time was recorded as well as difficulties and complications at each step of the procedure. The retrieved specimens were analyzed under a microscope to check if there was complete resection of the thymus. The animals in the survival group were monitored for 14 days. Gastroscopic and thoracoscopic examination and necropsy were performed in all animals at the end of the protocol (after the procedure in the acute animals and 14 days after when the survival animals were killed). The proximal esophagus of the pigs in the survival group was analyzed under a microscope to verify the healing process.

After the animal experiments, we performed the same procedure in a human female cadaver. Gastroscopic and thoracoscopic videos were recorded. The procedure time was recorded as well as difficulties and complications at each step of the procedure.

This study was approved by the ethical review board of Minho University (Braga, Portugal).

Pig preparation

All procedures were performed with the animals under general anesthesia with endotracheal intubation and mechanical ventilation. The pigs had no food $(8 \mathrm{~h})$ or water $(4 \mathrm{~h})$ before surgery. The pigs were premedicated with a combination of azaperone $(4 \mathrm{mg} / \mathrm{kg}$, intramuscularly [IM]), midazolam $(1 \mathrm{mg} / \mathrm{kg}, \mathrm{IM})$, and atropine $(0.05 \mathrm{mg} / \mathrm{kg}$, IM). Anesthesia was induced with propofol $(6 \mathrm{mg} / \mathrm{kg}$, intravenously [IV]) and maintained with continuous propofol infusion $(20 \mathrm{mg} / \mathrm{kg} / \mathrm{h}, \mathrm{IV})$ and buprenorphine $(0.05 \mathrm{mg} / \mathrm{kg}$, 

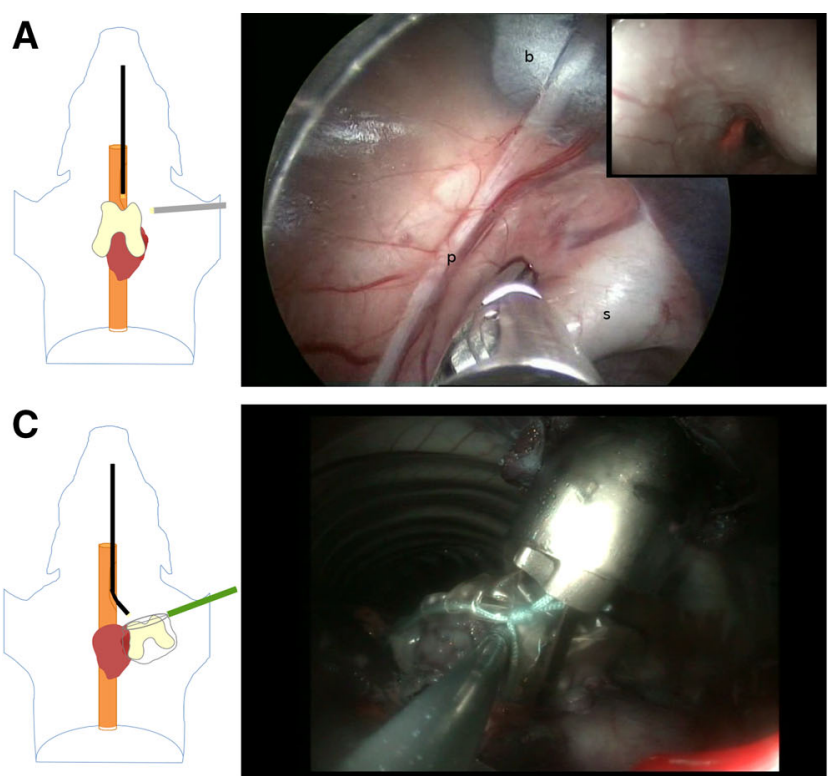

Fig. 2 Steps for hybrid endoscopic thymectomy (animal model). In $\mathbf{A}$ and $\mathbf{B}$, main image represents thoracoscopic view, and insets represent gastroscopic view. In $\mathbf{C}$ and $\mathbf{D}$, just gastroscopic image is represented. A Gastroscope going through the submucosal tunnel and thoracoscope showing the exact site for esophagotomy, between the left phrenic nerve (p), the left costocervical vein (c), and the left subclavian artery (s). B Dissection of the thymus (t) using a rigid

IM). The pig was placed in the dorsal decubitus position. Room ergonomics is shown in Fig. 1.

Human cadaver preparation

A 72-year-old female human cadaver weighting $75 \mathrm{~kg}$ was defrosted $48 \mathrm{~h}$ prior to the operation. The cadaver was placed in the dorsal decubitus position with her left arm abducted.

Surgical technique (animal model and human cadaver)

The main steps of the procedure described here are schematically illustrated in Fig. 2. An 11-mm trocar (CTF33, Kii Access System; Applied Medical, Rancho Santa Margarita, California) was inserted in the second or third intercostal space in the left anterior axillary line. Carbon dioxide $\left(\mathrm{CO}_{2}\right)$ was inflated through the transthoracic trocar, and pressure was maintained up to $6 \mathrm{~mm} \mathrm{Hg}$. An operative thoracoscope with a 5-mm working channel (Straight Forward Telescope $0^{\circ}$ 26034AA; Karl Storz GmbH, Tuttlingen, Germany) was introduced through the trocar. By using a rigid dissector (30310MLG; Karl Storz), the upper mediastinum was dissected allowing the identification of the esophagus with the help of gastroscope movements (inside the esophagus) and transillumination, between the left phrenic nerve, the left costocervical vein, and the left subclavian artery (Fig. 2A).

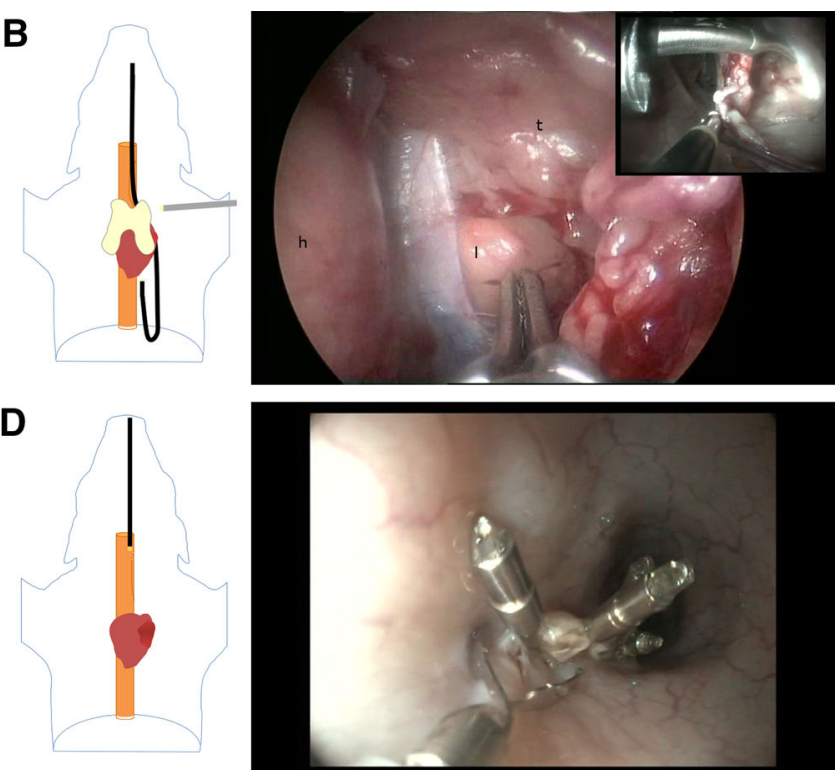

dissector introduced through the thoracoscope working channel and conter-traction using a flexible grasper introduced through the gastroscope. One can see the counter-lateral lung (l) and the heart (h). C A flexible grasper through the gastroscope introduces the specimens inside the endoscopic bag introduced through the transthoracic trocar. D Closing the mucosal incision of the esophagus with 5 hemoclips

A forward-viewing, single-channel gastroscope (13801PKS; Karl Storz) was advanced into the esophagus, identifying the position of the thoracoscope and determining the esophagotomy site. Five milliliters of saline solution were injected into the submucosa $8 \mathrm{~cm}$ proximal to the esophagotomy position using an injection needle (110231-01; Karl Storz), and a 1-cm longitudinal incision was made in the mucosa using a needle-knife (KD-11Q-1; Olympus, Tokyo, Japan) through the gastroscope working channel. Next an 6- to 8-cm long submucosal tunnel was created by blunt dissection. Esophagotomy was performed in the distal part of the submucosal tunnel (in the upper third of the esophagus).

While the submucosal tunnel was created in the esophagus, the left mediastinal pleura was opened and the left posterior limits of the thymus dissected using rigid instruments introduced through the transthoracic trocar. Once the transesophageal access was created, the dissection of the thymus was completed using both flexible (gastroscope) and rigid (thoracoscope) instruments (Fig. 2B). The vessels were ligated using electrocautery alone, either through the flexible coagulation grasper (gastroscope) or the rigid dissector (thoracoscope). All endoscopic procedures were performed under gastroscopic and thoracoscopic image control.

The specimens were retrieved through an endoscopic bag (Endopouch Retriever, Ethicon Endo-Surgery, Cincinnati, Ohio, USA) and introduced through the transthoracic trocar. 
Table 1 Results of 4 acute and 8 survival experiments

\begin{tabular}{|c|c|c|c|c|}
\hline Experiment & $\begin{array}{l}\text { Esophagotomy: } \\
\text { min, complications }\end{array}$ & $\begin{array}{l}\text { Thymus dissection and retrieval: min, } \\
\text { complications }\end{array}$ & $\begin{array}{l}\text { Closure: } \min , \\
\text { complications }\end{array}$ & $\begin{array}{l}\text { Acute versus } \\
\text { survival }\end{array}$ \\
\hline 1 & 10 & 43 & - & Acute \\
\hline 2 & 12 & 48 Small tear in the contralateral mediastinal pleura & - & Acute \\
\hline 3 & 15 & 353 Small tears in the pericardium & - & Acute \\
\hline 4 & 10 & 50 & - & Acute \\
\hline 5 & 14 & 36 Small tear in the pericardium & 15 & Survival \\
\hline 6 & 15 & 50 Small tear in the pericardium & 10 & Survival \\
\hline 7 & 15 & 25 Small tear in the pericardium & 5 & Survival \\
\hline 8 & 18 & 19 Small tear in the contralateral mediastinal pleura & 8 & Survival \\
\hline 9 & 10 & 38 Small tear in the contralateral mediastinal pleura & 12 & Survival \\
\hline 10 & 15 & 35 Small tear in the contralateral mediastinal pleura & 10 & Survival \\
\hline 11 & 12 & $\begin{array}{l}28 \text { Small tear in the pericardium partial resection } \\
\text { of contralateral mediastinal pleura }\end{array}$ & 5 & Survival \\
\hline 12 & 8 & 17 & 5 & Survival \\
\hline
\end{tabular}

For this, the surgeon handling the gastroscope grasped the specimens and put it inside the endoscopic bag (Fig. 2C).

In the survival group, in addition to the surgical procedure described, the esophageal mucosa was closed at the proximal edge of the submucosal tunnel using 4-5 flexible hemoclips (EZ Clip HX-110LR; Olympus). At the end of the procedure, the pneumothorax was drained using a thoracic tube introduced through the transthoracic trocar. No drain was left in place after the intervention. The trocar skin incision was sutured with 2 independent knots of nonabsorbable stitches.

\section{Postoperative care (survival animal group)}

At the end of the surgical intervention, all animals received a single dose of buprenorphine $(0.05 \mathrm{mg} / \mathrm{kg}$, IM) and meloxicam $(0.4 \mathrm{mg} / \mathrm{kg}, \mathrm{IM})$. Antibiotic ceftiofur hydrochloride ( $5 \mathrm{mg} / \mathrm{kg}$, IM) was repeated at 24-h intervals for 3 consecutive days. A regular diet was resumed $8 \mathrm{~h}$ after surgery.

The animals were closely monitored for any signs of postoperative complications, distress, behavior changes, anorexia, or weight loss. After the follow-up period, the animals were anesthetized for gastroscopic and thoracoscopic examination. They then were euthanized, and necropsy was performed to check for signs of cardiac or pulmonary complications. The proximal esophagus was analyzed under a microscope to verify the healing process.

\section{Results}

\section{Animal model}

The overall results of our study are summarized in Table 1. Dorsal decubitus and $\mathrm{CO}_{2}$ inflation permitted good visualization of the upper mediastinum. The coordination of the images from the thoracoscope and gastroscope allowed the determination of the ideal site for esophagotomy. Submucosal tunnel creation and esophagotomy were performed safely without incidents in all animals (Fig. 2A; Video 1). The mean time to perform the esophagotomy was $12.8 \pm 3.0 \mathrm{~min}$.

While the gastroscope operator was performing the submucosal tunnel, the surgeon with the thoracoscope opened the mediastinal pleura and began dissection of the left posterior limits of the thymus. We found that working with a single instrument without triangulation to be very limiting in terms of dissection. Nevertheless, leaving the anterior plane intact allowed the suspension of the thymus, facilitating the dissection of the posterior aspect when working together with the gastroscopic flexible instruments.

As soon as a transesophageal access was created, the instruments entering through both the gastroscope and thoracoscope created a triangulation very similar to the one experienced with the exclusively thoracoscopic approach. The flexible endoscope in retroflexion was essential for traction and conter-traction of the thymus. Lifting the thymus permitted a good dissection with the rigid dissector entering through the thoracoscope working channel. Pushing the thymus down was critical to separate it from the vessels in the upper mediastinum (Fig. 2B; Video 2). The flexible gastroscope was also useful for showing some parts of the thoracic cavity that could not be visualized with the 0-degree optic of the operative thoracoscope, i.e., the lateral thoracic wall and the entire diaphragm. Finally, retrieval of the specimens through an endoscopic bag introduced through the thoracic wall was only possible because the gastroscope gave visual control of the bag inside the chest and allowed the introduction of a grasper 
that was used to put the specimens inside the bag (Fig. 2C; Video 3).

As reported in Table 1, there were only minor incidents during endoscopic thymectomy. Small tears in the pericardium and in the counter lateral pleura did not have clinical impact on the animal well-being and did not implicate suturing. As for experiment 11, where a larger amount of pleura was resected along with the thymus, hemodynamic instability was noted, but the pig recovered rapidly when we stopped $\mathrm{CO}_{2}$ inflation. We achieved complete thymectomy in one piece in all experiments but one. In experiment number 9, two small pieces were resected. We safely retrieved the specimens using an endoscopic bag in all experiments (Fig. 3). The mean time to thymus dissection and retrieval was $35.33 \pm 11.4 \mathrm{~min}$. Complete thymus resection was achieved in all animals as verified by histological analysis (Fig. 4). Average specimens weight was $10.5 \pm 5.4 \mathrm{~g}$.

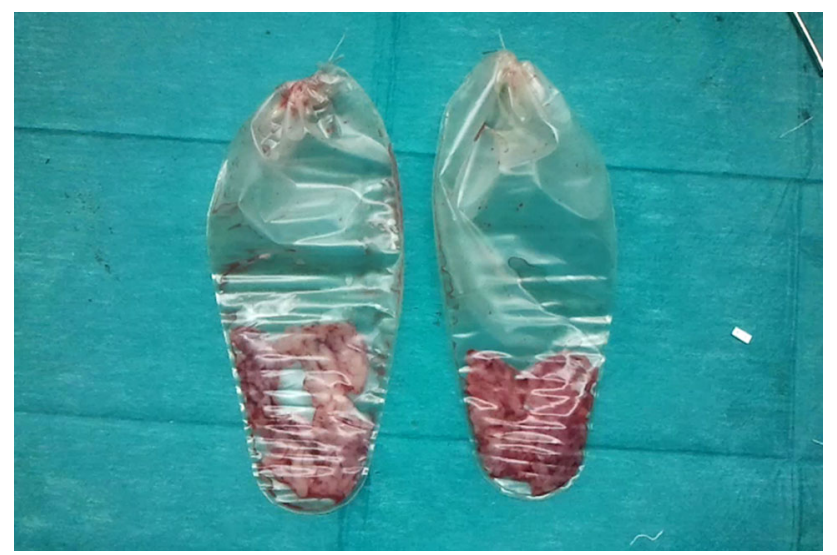

Fig. 3 Two specimens retrieved using an endoscopic bag from two consecutive experiments (animal model)
In the survival group, the esophageal mucosa was closed using hemostatic clips (Fig. 3D; Video 4). Thoracotomy was sutured after pneumothorax drainage. The mean time to esophageal mucosa closure was $8.8 \pm 3.4 \mathrm{~min}$. The total mean operative time in the survival group was $53.1 \pm 14.4 \mathrm{~min}$.

All 10 animals in the survival group lived for 14 days. After recovering from anesthesia, the pigs tolerated a regular diet started $8 \mathrm{~h}$ after surgery and deambulated freely, exhibiting normal behavior. No adverse events occurred during the survival period. Gastroscopic examination before sacrifice revealed complete esophageal closure in all animals. No esophageal strictures were found. In one of the animals, two esophageal hemoclips were still in place (Fig. 5).

Thoracoscopic and postmortem examination revealed pleural adhesions at the site of the surgical procedure

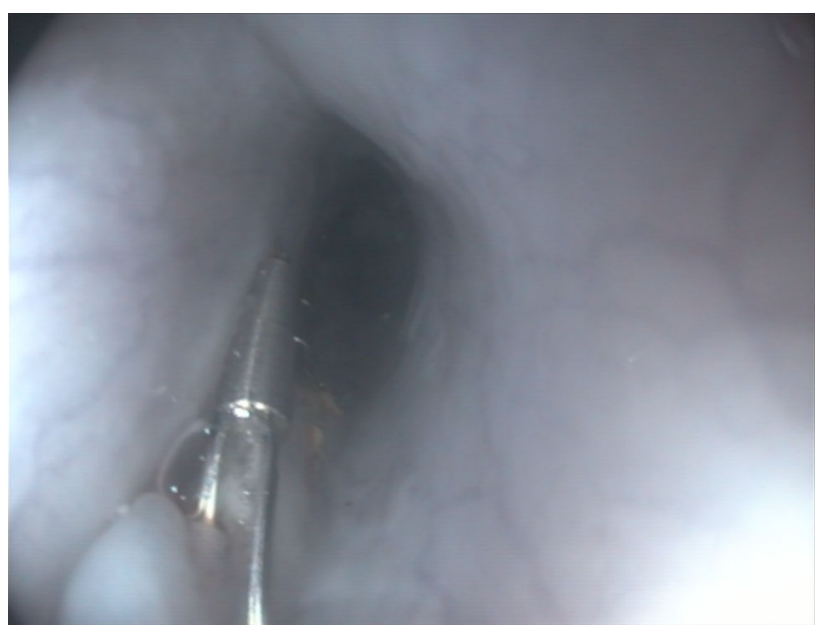

Fig. 5 Gastroscopic image on the 14th postoperative day of experiment 8 (animal model) showing 2 esophageal hemoclips in place
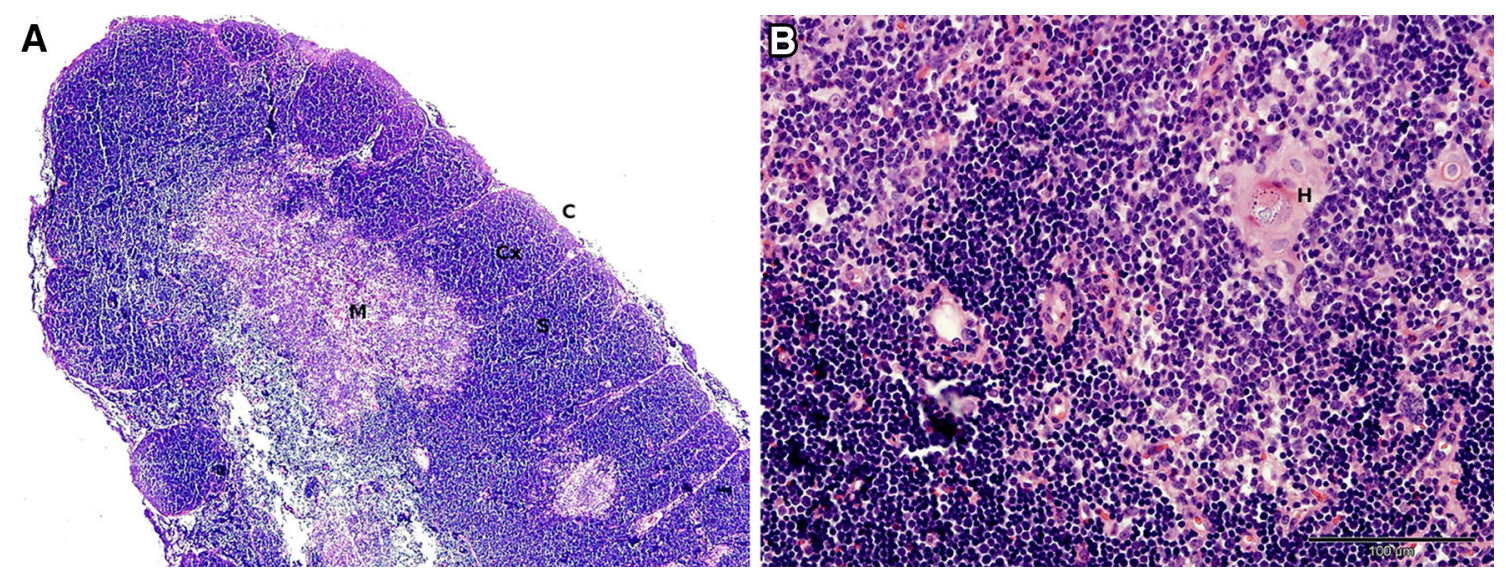

Fig. 4 Micrographs of thymic specimens of the pig (haematoxylin and eosin stain). A $4 \times$ Magnification: $C$ capsule, $C x$ cortex, $M$ medulla, $S$ septum. B $20 \times$ Magnification: $H$ Hassall corpuscle 
(Fig. 6). There were no signs of infection in the ipsi- or contralateral pleural space and lung parenchyma. Histological analysis of the proximal third of the esophagus revealed complete cicatrization of both the mucosal defect and the myotomy site in all the animals (Fig. 7).

\section{Human cadaver}

We found thoracoscopic visualization in the human cadaver very similar to the one we saw in the porcine model (Fig. 8). Submucosal tunnel creation and esophagotomy was performed safely without incidents, besides some difficulties related to dead tissues manipulation. The time to perform the esophagotomy was $23 \mathrm{~min}$.

We could not identify the thymus, because of the cadaver's older age. Even though, we dissected all the fat

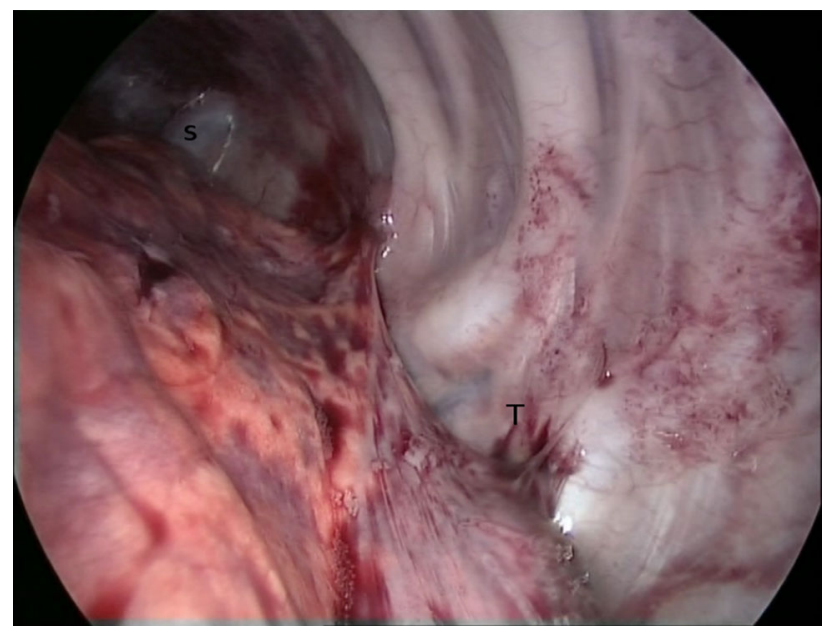

Fig. 6 Thoracoscopic image on the 14th postoperative day of experiment 12 (animal model) showing the thoracotomy site (T) after dissecting local adhesions and some pleural adhesions in the apex and next to the left subclavian artery (s) from major structures in the anterior mediastinum. Again, starting dissection posteriorly permitted suspension of the mediastinal fat, facilitating the dissection. Instruments entering both through the gastroscope and thoracoscope allowed good triangulation. Flexible gastroscope was useful in showing the lateral thoracic wall and the right-side of the anterior mediastinum. The overall time to mediastinal fat dissection and retrieval was $65 \mathrm{~min}$.

\section{Discussion}

Thymectomy plays an important role in the treatment of Myastenia Gravis and thymomas (that may coexist). Sternal approach for thymectomy has been widely used for

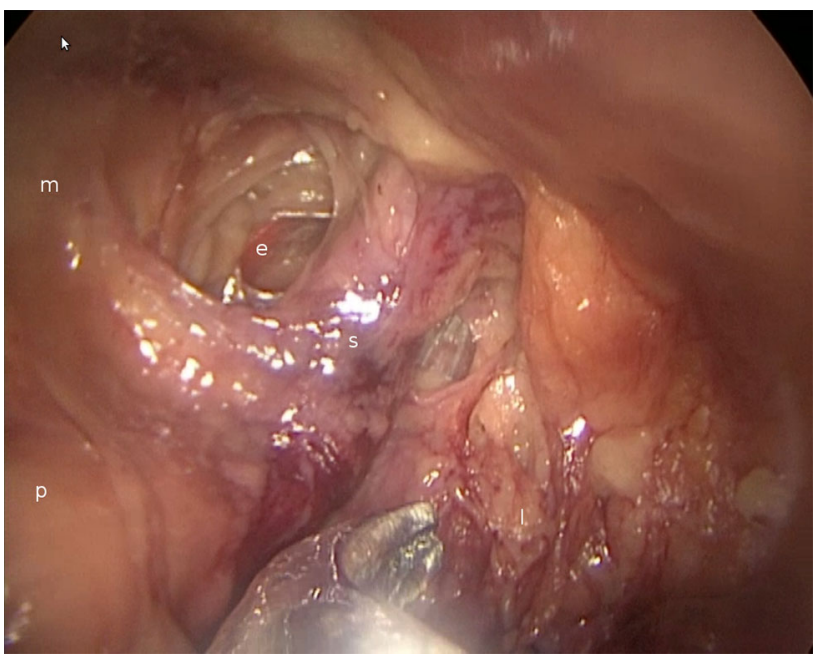

Fig. 8 Thoracoscopic view (left side) of the human cadaver. Exact site for esophagotomy
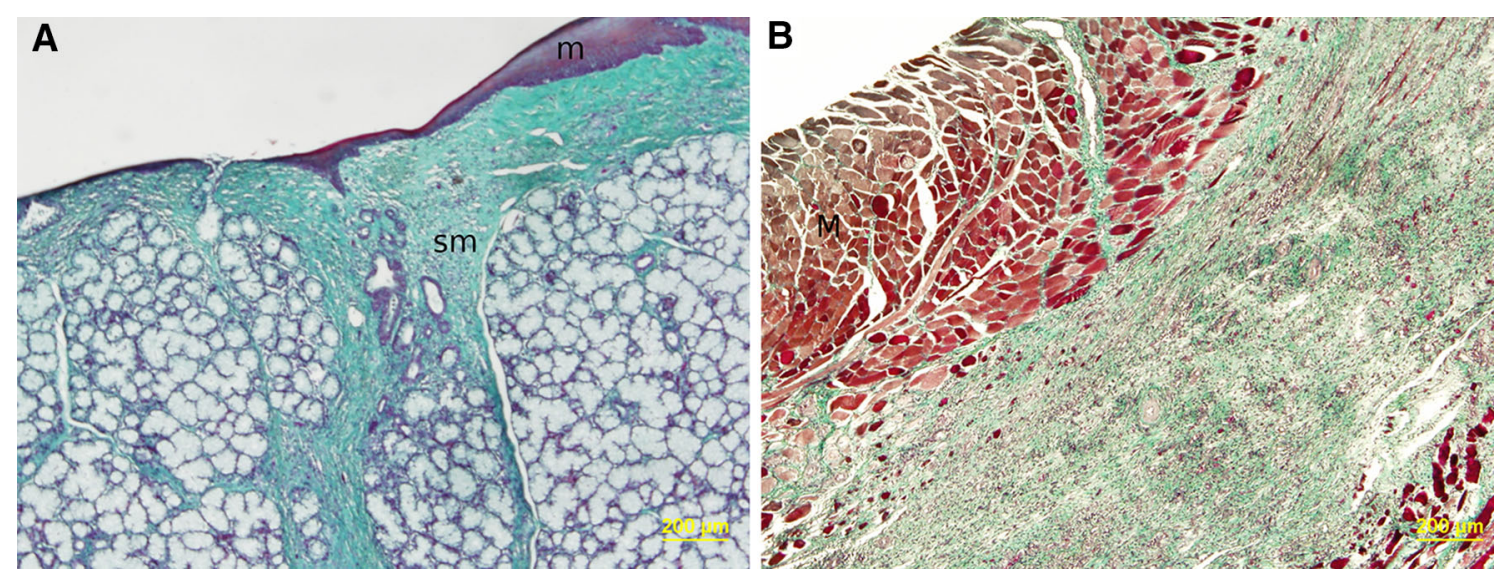

Fig. 7 Micrographs of esophageal specimens of the pig on the 14th postoperative day (Masson's thricrome stain). A Site of mucosal incision: $m$ mucosa, $s m$ submucosa. B Site of myotomy: $M$ outter muscle layer 
decades. VATS thymectomy has great advantage over sternotomy because of avoidance of muscle division and bone fractures, allowing for diminished duration and intensity of pain and shorter time to return to full activity [19]. Previous studies comparing different operative techniques showed that VATS thymectomy produced a longterm clinical outcome equivalent to that of the extended sternal approach, with lower complication rates [20, 21]. Although some of the reports have suggested the need to perform a bilateral VATS, most perform from the right chest [22]. Approach from the left chest can also be used, but the arch of aorta and the brachycephalic vein might difficult thoracoscopic access [23].

In the NOTES era, transesophageal endoscopic surgery is emerging as an alternative to the classic thoracoscopic surgery. The theoretical advantages of NOTES over open surgery and conventional thoracoscopy include decreased postoperative pain, reduction/elimination of general anesthesia, performance of procedures in an outpatient or even office setting, and possible cost reduction. Additionally, eliminating a skin incision avoids associated complications such as wound infections and hernias, and facilitates a shorter hospital stay, faster return to regular activity, improved cosmetic outcomes, and increased overall patient satisfaction. Rolanda et al. introduced the concept of hybrid thoracic NOTES [16]. By introducing a transthoracic trocar, the authors overcame some potential risks of the transesophageal approach, i.e., blind esophagotomy creation, thoracic drainage at the end of the procedure, and triangulation of instruments.

We have already described several advantages of using the single transthoracic assistance, in previous reports [17, 18]. First of all, the trocar site is used for $\mathrm{CO}_{2}$ inflation and pressure control. At the end of the experiments, it permits tube insertion and acute pleural drainage. This port might be important in the human setting, as thoracoscopic procedures always need some time of thoracic drainage. Transthoracic visualization allows control of esophagotomy creation, performed from the inside to the outside of the esophagus, pointing out the exact place where it should be created, side and level, and avoiding lesions of arteries, veins, and nerves. The visual control provided by the thoracoscope permits guiding of instruments introduced transesophageally and manipulated through the mouth.

The concurrent use of two opposite sites for the entrance of scopes and respective instruments allowed for the establishment of regular triangulation and counter-traction thus simulating the two hand movements of the surgeon and promoting secure manipulation of tissues, careful dissection, and effective electrocoagulation for hemorrhagic control. As mentioned before, the flexible endoscope inside the thorax makes possible to examine the whole cavity including sites that rigid transthoracic endoscopes cannot reach-namely the chest wall and counter-lateral mediastinum. Furthermore, the gastroscopic visual control permits guiding of blind-rigid instruments introduced through the transthoracic trocar, as happened with the endoscopic bag. Using the intrathoracic visual control provided by the gastroscope, the surgeon working through the thoracic wall positioned and opened the endoscopic bag. Then, the surgeon handling the gastroscope put the specimens inside the bag. We opted to extract the thymus using this method, because of the risk of disseminating thymus cells along the esophageal submucosal tunnel.

As stated before, most surgeons perform thoracoscopic thymectomy from the right chest or perform bilateral VATS. In our study, thymectomy was done from the left side, because transthoracic visual control for safe esophagotomy was only possible from the left chest. Again, the fact of having a flexible gastroscope entering from the apex permitted clear visualization of both sides of the anterior mediastinum and thoracic cavities. So, approaching the thymus from the left was not a limitation in our experiments.

The submucosal tunnel before esophagotomy creates a valve system that collapses as soon as the procedure is completed. Some authors have suggested leaving the mucosal defect open [24]. Mediastinal and lung infection could be of some concern. So we opted to close the mucosa with hemoclips, and this technique was found to be effective in all of our survival experiments. And as shown, combining the esophageal submucosal tunnel with antibiotic prophylaxis was enough to avoid any type of infection. Esophageal submucosal tunnel with antibiotic prophylaxis has been used for per oral endoscopic myotomy (POEM) for the treatment of achalasia. POEM uses submucosal dissection to reach and divide the inner muscle layer of the cardia. Although there is not a true esophagotomy in POEM, outcomes are excellent, and clinical data support theoretical advantages of transesophageal endoscopic surgery over conventional laparoscopy and thoracoscopy [25]. Despite this, true advantages of transesophageal access for thoracoscopic procedures over the risk of mediastinal infection are still a matter of concern.

We always thought the animal model could be a limitation of our study. Although the esophageal and cardiopulmonary porcine anatomy is very similar to that of humans, the sternum of the pig protrudes, resembling pectus carinatum. Surprisingly, we did not find that much difference when performing the hybrid endoscopic approach in the human cadaver. Even though, working space is described as a major hurdle in VATS thymectomy, specially in larger tumors. For that, some authors suggest retracting the sternum using a $10 \mathrm{~mm}$ cotton string caught on the stainless steel rod at the head of the table and tied to 
the hook of a Kent retractor at the thigh level [10]. Because of the age of the Human cadaver, we could not identify any thymus tissue. The average size of the resected thymus in patients with thymoma is bigger than the one of our study in porcine model. On one hand, identification of the limits of a large thymus is easier than a small one mixed with the surrounding fat. On the other hand, manipulating and dissecting "healthy" thymus might be easier than pathologic, infiltrating ones.

Survival experiments were essential to prove that transesophageal HET was feasible and reliable. The cadaveric experiment proved that technically HET might be translated to humans. We believe that in the future HET could be regarded as an alternative to classic thoracoscopic approach for patients requiring thymectomy.

Acknowledgments This project was funded by the FCT Grants project PTDC/SAU-OSM/105578/2008.

Disclosures J Correia-Pinto is a consultant for Karl Storz GmbH. Aníbal Ferreira, Alice Miranda, Carla Rolanda have no conflict of interest.

\section{References}

1. Allen MS, Deschamps C, Lee RE et al (1993) Video-assisted thoracoscopic stapled wedge excision for indeterminate pulmonary nodules. J Thorac Cardiovasc Surg 106:1048-1052

2. Hazelrigg SR, Nunchuck SK, LoCicero J et al (1993) Videoassisted thoracic surgery study group data. Ann Thorac Surg 36:1039-1043

3. Lewia RJ, Caccavale RJ, Sisler GE et al (1992) One hundred consecutive patients undergoing video-assisted thoracic operations. Ann Thorac Surg 54:421-426

4. Coltharp WH, Arnold JH, Alford WC et al (1992) Videothoracoscopy: improved technique and expanded indications. Ann Thorac Surg 53:776-778

5. Landreneau RJ, Dowling RD, Castillo WM et al (1992) Thoracoscopic resection of an anterior mediastinal tumor. Ann Thorac Surg 54:142-144

6. Yim AP, Wan S, Lee TW et al (2000) VATS lobectomy reduces cytokine responses compared with conventional surgery. Ann Thorac Surg 70:243-247

7. Ruckert JC, Walter M, Muller JM (2000) Pulmonary function after thoracoscopic thymectomy versus median sternotomy for myasthenia gravis. Ann Thorac Surg 70:1656-1661

8. Mack MJ, Landreneau RJ, Yim AP et al (1996) Results of videoassisted thymectomy in patients with myasthenia gravis. J Thorac Cardiovasc Surg 112:1352-1360
9. Agasthian T (2011) Can invasive thymomas be resected by videoassisted thoracoscopic surgery? Asian Cardiovasc Thorac Ann 19:225-227

10. Takeo S, Tsukamoto S, Kawano D et al (2011) Outcome of an original video-assisted thoracoscopic extended thymectomy for thymoma. Ann Thorac Surg 92:2000-2005

11. Sumiyama K, Goustout CJ, Rajan E et al (2007) Transesophageal mediastinoscopy by submucosal endoscopy with mucosal flap safety valve technique. Gastrointest Endosc 65:679-683

12. Lima E, Henriques-Coelho T, Rolanda C et al (2007) Transvesical thoracoscopy: a natural orifice translumenal endoscopic approach for thoracic surgery. Surg Endosc 21:854-858

13. De Palma GD, Siciliano S, Addeo P et al (2010) A NOTES approach for thoracic surgery: transgastric thoracoscopy via a diaphragmatic incision in a survival porcine model. Minerva Chir 65:11-15

14. Yang C, Liu HP, Chu Y et al (2010) Natural orifice transtracheal evaluation of the thoracic cavity and mediastinum. Surg Endosc 24:2905-2907

15. Moreira-Pinto J, Ferreira A, Rolanda C, Correia-Pinto J (2012) Natural orifice transesophageal endoscopic surgery: state of the art. Minim Invasive Surg 2012:896952

16. Rolanda C, Silva D, Branco C et al (2011) Peroral esophageal segmentectomy and anastomosis with single transthoracic trocar assistance: a step forward in thoracic NOTES. Endoscopy 43:14-20

17. Moreira-Pinto J, Ferreira A, Miranda A et al (2012) Transesophageal pulmonary lobectomy with single transthoracic port assistance: study with survival assessment in a porcine model. Endoscopy 44:354-361

18. Moreira-Pinto J, Ferreira A, Miranda A, Rolanda C, CorreiaPinto J (2012) Left atrial appendage ligation with single transthoracic port assistance: a study of survival assessment in a porcine model (with videos). Gastrointest Endosc 75:1055-1061

19. Yu L, Zhang XJ, Ma SM et al (2012) Thoracoscopic thymectomy for myasthenia gravis with and without thymoma: a single-center experience. Ann Thorac Surg 93:240-244

20. Meyer DM, Herbert MA, Sobhani MC et al (2009) Comparative clinical outcomes of thymectomy for myasthenia gravis performed by extended transsternal and minimally invasive approaches. Ann Thorac Surg 87:385-391

21. Mack MJ, Scruggs G (1998) Video-assisted thoracic surgery thymectomy for myasthenia gravis. Chest Surg Clin North Am 8:809-825

22. Parikh K, Vaidya A, Jain R (2011) Preliminary results of VATS thymectomy for pediatric myasthenia gravis. Pediatr Surg Int 27:595-598

23. Loscertales J, Ayarra Jarne J, Congregado M et al (2004) Videoassisted thoracoscopic thymectomy for the treatment of myasthenia gravis. Arch Bronconeumol 40:409-413

24. Gee DW, Willingham FF, Lauwers GY et al (2008) Natural orifice transesophageal mediastinoscopy and thoracoscopy: a survival series in swine. Surg Endosc 22:2117-2122

25. Inoue $\mathrm{H}$, Tianle KM, Ikeda $\mathrm{H}$ et al (2011) Peroral endoscopic myotomy for esophageal achalasia: technique, indication, and outcomes. Thorac Surg Clin 21:519-525 